\title{
Examining Regulatory Focus in the Information Processing of Imagery and Analytical Advertisements
}

\author{
Rajat Roy and Ian Phau \\ Curtin Business School, Perth, Western Australia
}

\begin{abstract}
The results of two experimental studies show that matching a promotion (prevention) focus with imagery (analytical) information in an advertisement results in higher advertising effectiveness, together with increased intention to purchase. Mediation analyses show that the impact of a regulatory focusinformation matching in evaluation and purchase intention-is partially mediated by the fluency of processing. Matching is also found to increase message persuasiveness, and this effect is fully mediated by processing fluency. Furthermore, in response to imagery (analytical) information types, promotion (prevention)focused subjects are found to engage imagery (analytical) processing styles to support their regulatory orientation.
\end{abstract}

In their everyday lives, consumers are often invited to imagine their consumption experiences through product advertisements. For example, advertisements with phrases such as "imagine your perfect home" or "imagine yourself in Hawaii" are common and can elicit imagery processing in consumers. Imagery processing or "imagery" is a process by which sensory information is represented in the working memory and has been distinguished from the more data-driven analytical processing (Thompson and Hamilton 2006; MacInnis and Price 1987). Typically, in consumer behavior studies, imagery (versus analytical) processing has been evoked by intrinsic message cues such as narrative and descriptive words rather than statistical information (Bolls and Muehling 2007; Thompson and Hamilton 2006; Keller and Block 1997).

In addition to message characteristics, imagery has also been shown to be moderated by variables such as instructions to imagine, individual differences, and situational context

Address correspondence to Rajat Roy, Curtin Business School, GPO Box U 1987, Perth, Western Australia 6845. E-mail: r.roy@cbs. curtin.edu.au

Rajat Roy (PhD, Nanyang Technological University, Singapore) is a Lecturer in the School of Marketing, Curtin University.

Ian Phau (PhD, Henley Management College, UK) is a Professor in the School of Marketing, Curtin University.

Color versions of one or more of the figures in the article can be found online at www.tandfonline.com/ujoa. (e.g., Bagozzi 2008; Wyer, Hung, and Jiang 2008; Thompson and Hamilton 2006). However, given that consumers are driven by goals (Lin and Shen 2012) and are exposed to both imagery and analytical information in their daily lives (e.g., through product advertisements), the role of motivation in information processing is underresearched (Bagozzi 2008; Wyer, Hung, and Jiang 2008). A higher-order goal such as regulatory focus (Higgins 1997) has been shown to activate mindsets and influence choice of information in decision making. For example, current literature posits that matching a specific type of information (e.g., hedonic, affective, abstract) with a certain regulatory focus (e.g., promotion) can lead to better persuasion, a phenomenon also known as regulatory fit (e.g., Kees, Burton, and Tangari 2010; Aaker and Lee 2001).

The theory of regulatory focus proposes that a strategic orientation to approaching a positive (or moving away from a negative) end state can create different motivations, referred to as a promotion (prevention) focus (Higgins 1997). Research evidence shows that different mind-sets activated under a promotion or prevention focus can guide information choice in judgment and decision making, for example, product evaluation and choices (Lin and Shen 2012; Pham and Avnet 2004). For example, a promotion focus has been associated with hedonic consumption, impulsive choices, and creative approaches to decision making (Sengupta and Zhou 2007; Chernev 2004; Friedman and Forster 2001). In comparison, a prevention focus has been associated with utilitarian choices and less innovative approaches to decision making.

In the marketing literature, an association has long been made between hedonic consumption, affect, and imagery, especially in the context of experiential consumption (Bolls and Muehling 2007; MacInnis and Price 1987; Hirschman and Holbrook 1982). Despite this linkage, no research has been undertaken to explore whether regulatory focus can influence imagery processing. Scholars, such as Petrova and Cialdini (2008), clearly recommend the need to uncover additional processes through which imagery influences consumers and the conditions under which such effects occur. Furthermore, although imagery has normally been shown to influence 
attitude positively, it can also have a detrimental effect (Petrova and Cialdini 2008; Kisielius and Sternthal 1986). Under certain conditions, for example, instructions to imagine a consumption scenario may increase cognitive elaboration and decrease persuasion as subjects access both positive and negative information from their memory (Kisielius and Sternthal 1986).

This work addresses the previously mentioned gaps in the literature. First, we show that mere induction of regulatory focus can activate imagery (analytical) processing in individuals on exposure to imagery and analytical message attributes in advertisements. This happens without any explicit instructions, for example, asking subjects to adopt a specific processing style. We argue that since regulatory motivation engages different mental approaches (Packer and Cunningham 2009; Pennington and Roese 2003; Friedman and Forster 2001), a certain mind-set, for example, promotion (prevention), is more suitable for a specific processing style, for example, imagery (analytical). Further, matching regulatory focus with message attributes results in enhanced persuasion and advertising effectiveness. To the best of our knowledge, no earlier research has tested these propositions.

In the following section, the relevant theoretical background for the research hypotheses is reviewed, after which the article reports on two studies in support of the main premise. A discussion of the results, implications, and suggestions for future research follows the report.

\section{THEORETICAL FRAMEWORK AND HYPOTHESIS DEVELOPMENT}

\section{Imagery and Analytical Processing}

Imagery in the current literature is conceptualized as a multidimensional cognitive construct, a process by which sensory information is represented in the working memory (Petrova and Cialdini 2008; MacInnis and Price 1987). The evocation of imagery is often multisensory but might engage a single dimension such as sight, or multiple experiences such as sight, smell, taste, and tactile sensations. Furthermore, following this conceptualization, imagery can be described across several unique and related dimensions such as vividness, referring to the clarity of the images generated, or controllability, meaning how it is held in the mind and/or altered in specific ways (Petrova and Cialdini 2008; MacInnis and Price 1987).

Imagery as a mental process is also referred to as imagery processing in the literature (Bolls and Muehling 2007). Imagery processing is therefore a nonverbal, sensory representation of perceptual information in the memory as opposed to more semantic, reason-based processing (Childers, Houston, and Heckler 1985). According to Keller and McGill (1994), under conditions of high cognitive elaboration, imagining a product experience can trigger affect. However, research evidence shows that imagery's effect on product preference remains significant even after controlling for affect (Escalas 2004; Mani and MacInnis 2001).

Analytical processing, on the other hand, is data driven and focuses on verbal retrieval and encoding rather than internal sensory experiences (Thompson and Hamilton 2006; MacInnis and Price 1987). In this approach, the decision maker undertakes an attribute-based evaluation of a product to assess the overall value of the target product (Sujan 1985). For example, in an analytical processing mode, consumers may arrive at an evaluation by summarizing the features of a brand (Thompson and Hamilton 2006). Analytical processing, in this sense, is the more careful processing of information to arrive at a logical decision.

It is important to distinguish between imagery and analytical information processing styles and the imagery and analytical attributes of a message. Conceptually, different aspects of message attributes are manipulated to evoke imagery or analytical processing in participants. According to recent literature, imagery has been manipulated in various ways; these include the presence versus the absence of pictures (Kisielius and Sternthal 1986), the provision of narrative versus statistical information (Keller and Block 1997), and even instructions to imagine (for a detailed review, see Petrova and Cialdini 2008). For example, Bolls and Muehling (2007) used intrinsic message cues such as "sound effects" or "descriptive language" to evoke imagery for their radio advertisements. Similarly Thompson and Hamilton (2006) used descriptor sentences before product attributes to trigger imagery. The extant literature also distinguishes imagery and analytical processing styles to be conceptually distinctive as compared to "abstract versus concrete" or "bottom-up versus top-down" processing modes (Smith and Trope 2006; Gasper 2004).

\section{Regulatory Focus and Preference for Imagery and Analytical Information}

Regulatory focus theory assumes that self-regulation operates differently when serving fundamentally different needs, such as the distinct survival needs of nurturance and security (Higgins 1997). Regulatory focus theory proposes that nurturance regulation involves a promotional focus - a regulatory state concerning advancement, accomplishment, and aspirations (i.e., a concern with the presence or absence of a positive outcome). In contrast, security-related regulation involves a prevention focus - a regulatory state concerning protection, safety, and responsibility (i.e., a concern with the absence or presence of a negative outcome).

A promotion focus typically relies on approach-oriented strategies and is characterized by an eager form of exploration that aims to maximize gains (Pham and Avnet 2009). A prevention focus, on the other hand, relies on avoidance-oriented strategies and is characterized by a vigilant form of exploration that aims to prevent loss (Pham and Avnet 2009). It is important to note that regulatory focus is a motivational state 
and the two systems can coexist independently of each other in every person. Each focus can be further activated temporarily, for example, a promotion focus can be activated by priming a person's "ideals," while a prevention focus can be activated by priming a person's "oughts" (Higgins 1997).

The extant research shows that focusing on a positive end state informs a promotional focus that the current environment is benign and requires no particular action (Friedman and Forster 2001). Promotion-induced eagerness therefore encourages risk-seeking behavior and has been found to promote impulsive purchases (Sengupta and Zhou 2007), preference for hedonic products (Chernev 2004), and the use of heuristics in decision making (Pham and Avnet 2004).

In contrast, focusing on a negative end state informs a prevention focus that the environment is problematic and that specific actions are needed to rectify the situation (Friedman and Forster 2001). As a result, people assess matters carefully, in a precise and detailed fashion, to avoid an undesirable end state (Zhu and Meyers-Levy 2007; Friedman and Forster 2001). Consequently, the risk-averse nature of prevention-oriented people promotes a preference for functional products (Chernev 2004) and the use of substantive information in decision making (Pham and Avnet 2004).

Research evidence shows that when the information presented for evaluation matches a certain regulatory state, it results in enhanced persuasion, a phenomenon also referred to as regulatory fit in the literature (Wang and Lee 2006; Higgins et al. 2003). For example, subjects have been found to exhibit a preference for a certain product type when it is described in terms of features that match their regulatory focus (e.g., toothpaste with a teeth-whitening feature for a promotion focus as opposed to decay prevention for a prevention focus). Similarly, in judgment, promotion (prevention)-focused subjects exhibit better evaluation when they rely on affective versus substantive responses (Pham and Avnet 2004).

So far, we have argued that regulatory focus activates a different mind-set in individuals, which instills preferences for different types of information for judgment and decision making. In particular, a promotional mind-set seems to promote experiential consumption, as evidenced through a reliance on affect and hedonic product features in consumption (Lin and Shen 2012; Chernev 2004; Pham and Avnet 2004). The marketing literature has long argued that hedonic consumption, affect, and imagery are closely linked in the domain of experiential consumption (Chernev 2004; MacInnis and Price 1987; Hirschman and Holbrook 1982). For example, hedonic consumption has often been described as affect laden as it encompasses pleasure, fantasy, fun, and feelings (MacInnis and Price 1987; Hirschman and Holbrook 1982). Pursuing hedonic consumption, for example, by listening to music, can evoke mental images and induce affect (Bolls and Muehling 2007; Escalas 2004).

On the other hand, a prevention mind-set prefers logical decisions based on substantive and practical information as evidenced through reliance on utilitarian features in product consumption (Lin and Shen 2012; Chernev 2004; Pham and Avnet 2004). People with such a mind-set are more persuaded by rule-based judgment leading to decisions that can be justified (Shafir, Simonson, and Tversky 1993). Matching a certain regulatory focus with the relevant information type will therefore enhance message persuasiveness even in the context of advertisements (Sung and Choi 2011; Aaker and Lee 2001). This will result in a higher evaluation of the advertisement and brand, as well as greater purchase intention. Therefore, we propose the following hypotheses:

\begin{abstract}
H1a: Promotion-focused subjects will form higher evaluations of (a) attitude toward the advertisement, (b) attitude toward the brand, and (c) purchase intentions when they rely on imagery information in the advertisement in comparison with prevention-focused participants.
\end{abstract}

H1b: Prevention-focused subjects will form higher evaluations of (a) attitude toward the advertisement, (b) attitude toward the brand, and (c) purchase intentions when they rely on analytical information in the advertisement in comparison with promotion-focused participants.

H2a: The reliance of promotion-focused participants on imagery information in advertisements will lead to enhanced message persuasiveness in comparison with prevention-focused counterparts.

H2b: The reliance of prevention-focused participants on analytical information in advertisements will lead to enhanced message persuasiveness in comparison with promotion-focused counterparts.

\section{The Mediation Process Underlying Persuasion}

The research evidence shows that judgment is affected not only by the content of the relevant product information but also by the fluency with which such information is generated and processed (Petrova and Cialdini 2005; Labroo and Lee 2006). Fluency refers to how effortless processing is, especially when the information presented is consistent with the mode of processing (Petrova and Cialdini 2005). For example, fluency of processing has been found to be enhanced (reduced) when subjects asked to imagine a consumption scenario are presented with imagery (factual) information (Thompson and Hamilton 2006). Decreased fluency in turn negatively affects the product evaluation (Petrova and Cialdini 2005).

In the specific context of regulatory focus and information matching, variables such as fluency of processing (Labroo and Lee 2006; Lee and Aaker 2004), better message recall (Aaker and Lee 2001), enhanced feature attractiveness (Wang and Lee 2006), and perceived diagnosticity (Pham and Avnet 2004) have been found to influence message persuasion. In this research, based on the extant literature (Petrova and Cialdini 2005; Thompson and Hamilton 2006), we posit that 
matching the focus with the relevant information will influence the judgment favorably as it will help consumers process the information effortlessly.

\begin{abstract}
H3: The effect of matching regulatory focus and information on evaluation, purchase intention, and message persuasiveness will be mediated by the enhanced processability of the relevant information type.
\end{abstract}

\section{Regulatory Focus and Information Processing Styles}

A promotional mind-set has also been associated with more creative approaches to problem solving (Friedman and Forster 2001) and more abstract mental construal linked with temporally distant goals (Pennington and Roese 2003). Research findings show that imagery is significantly associated with creativity and demands a higher level of abstraction in the mental construal process (Vasquez and Buehler 2007). Prevention focus, on the other hand, engages a different mental approach as evidenced by less novel responses to problem solving (Pennington and Roese 2003; Friedman and Forster 2001).

Research into neuroimaging clearly identifies the different mental approaches engaged under promotion and prevention foci (Packer and Cunningham 2009). This research indicates that the induction of a promotion goal prompts the activation of frontal regions of the brain, whereas prevention goals cause activation of posterior regions (Packer and Cunningham 2009). Brain activities also shift from more posterior to more anterior regions as cognitions increase in their level of abstraction. This probably suggests that, as promotion and prevention foci engage different mental processes, exposure to different message attributes is likely to trigger matching processing styles in individuals. We propose the following additional hypotheses:

\begin{abstract}
H4a: In response to imagery information in an advertisement, promotion-focused participants will engage in a higher imagery processing style than prevention-focused participants.
\end{abstract}

H4b: In response to analytical information in an advertisement, prevention-focused participants will engage in a higher analytical processing style than promotion-focused participants.

\section{STUDY 1}

\section{Method}

The study used a two (regulatory focus: promotion versus prevention) by two (advertisement type: imagery versus analytical) between-subjects experimental design. A total of 91 undergraduate students (63 females, mean age 22.2 years) from a large Australian university participated in the experiment in exchange for course credit. All the participants were randomly assigned to one of the four conditions.

Pretest for product stimulus.. The product stimulus for this study was an advertisement for a fictitious brand of car,
"Allegre." Following current literature (Bolls and Muehling 2007; Thompson and Hamilton 2006), two different versions (i.e., imagery and analytical) of an advertisement for the fictitious brand of car were used. The advertised brand of car had four superior attributes: sunroof, sound system, warranty, and security system. The imagery version used descriptors before an attribute, while the analytical condition had the same attribute information displayed using a matrix. Both the advertisements were similar in terms of the graphics, for example, picture of the car, size of the picture, and colors. A pretest ( $n$ $=22$ ) confirmed that a short description of the product attributes was found to be more imagery based than the advertisement using a matrix to display information, the latter being perceived as analytical $(M=4.6$ and $M=3.1$, respectively, $p$ $<0.01)$. The stimuli are presented in appendix.

Pretest for regulatory focus manipulation. The manipulation is based on Higgins's (1997) classification of human goals and adopted by Pham and Avnet (2004). In this procedure, ideals (oughts) were primed in subjects by asking them to write about their present and future hopes and aspirations (duties and obligations), following which they completed the key dependent variable meant to capture the conflict between these goals. Results of a pretest $(n=21)$ confirmed that this manipulation was successful in the Australian context. Participants in the primed oughts condition placed relatively greater emphasis on oughts versus ideals $(M=5.1)$ than did the participants in the primed ideals condition $(M=2.94,(F(1,19)=74.16), p<0.001)$.

Procedure and measures. Using a cover story, subjects were told that they were participating in two seemingly unrelated studies. In the first part, participants' regulatory focus was primed (Pham and Avnet 2004), while in the second part participants were asked to evaluate the advertisements for Allegre, a fictitious car brand entering the Australian market. The key dependent variables used for this study were attitude toward the advertisement, brand, and purchase intention, along with other process measures.

Attitude toward the advertisement and the brand was measured using five 9-point scale items-the extent to which subjects considered the advertisement and the brand to be bad/ unpleasant/worthless/unfavorable/not interesting. Both the measures showed good reliability (Cronbach's $\alpha=0.945$ and 0.968 , respectively). Purchase intention was measured using a single 9-point scale item-how likely the participants were to choose the new Allegre-anchored at Definitely would not/ Certainly would.

After answering the questions on dependent measures, the participants further completed fluency and style of processing measures for the analytical and imagery conditions (Thompson and Hamilton 2006). All the items employed a 9-point Likert scale with Strongly disagree/Strongly agree as the end points. For example, imagery fluency was measured using three items, namely, "It was easy to create a mental image"; "The mental images were clear to me"; and "It took a long time to imagine the advertised brand." Similarly, analytical fluency was 
TABLE 1

Study 1: Dependent Variables as a Function of Regulatory Focus and Ad Type

\begin{tabular}{|c|c|c|c|c|c|c|}
\hline \multirow[b]{2}{*}{ Variables } & \multicolumn{2}{|c|}{ Attitude toward ad } & \multicolumn{2}{|c|}{ Attitude toward brand } & \multicolumn{2}{|c|}{ Purchase intention } \\
\hline & Imagery ad & Analytical ad & Imagery ad & Analytical ad & Imagery ad & Analytical ad \\
\hline Promotion & $\begin{array}{c}6.7 \\
(1.1)\end{array}$ & $\begin{array}{c}4.2 \\
(1.6)\end{array}$ & $\begin{array}{c}6.9 \\
(1.1)\end{array}$ & $\begin{array}{c}5.0 \\
(1.8)\end{array}$ & $\begin{array}{c}6.0 \\
(2.0)\end{array}$ & $\begin{array}{c}3.5 \\
(1.4)\end{array}$ \\
\hline Prevention & $\begin{array}{c}4.3 \\
(1.4)\end{array}$ & $\begin{array}{c}6.3 \\
(1.6)\end{array}$ & $\begin{array}{c}5.3 \\
(1.7)\end{array}$ & $\begin{array}{c}7.1 \\
(1.5)\end{array}$ & $\begin{array}{c}3.8 \\
(1.8)\end{array}$ & $\begin{array}{c}6.1 \\
(2.1)\end{array}$ \\
\hline
\end{tabular}

Note. Figures in parentheses represent standard deviation.

measured with items such as "It was easy to consider the brand feature by feature"; "I understood the brand's features very well"; and "The brand's advantages were very clear."

Imagery processing style was measured through three items, namely, "I imagined myself in the car"; "I savored visions of the car"; and "I experienced a sense of fun in thinking about the car," on a 9-point scale with Not very much/A great deal as the end points. Analytical processing consisted of four items: "I evaluated the car feature by feature rather than evaluating the car as a whole"; "My evaluation of the car was based primarily on its features"; "I tried to use as much information about the features as possible"; and "I carefully evaluated the car on several different features" with the same end points. In addition, single-item measures were used to gauge involvement and familiarity with the product category.

\section{Results}

Dependent measures. The results of a one-way ANOVA showed that neither involvement nor familiarity with the product category differed significantly across independent variables (all $p>0.05$ ); thus they were dropped from further statistical analyses.

The three major dependent variables-namely attitude toward the advertisement, attitude toward the brand, and purchase intention-were subjected to a MANOVA. None of the main effects was significant. As predicted, a two-way interaction between regulatory focus and advertisement type was significant for all the dependent variables $(F(3,85)=21.4$, $p<0.001$, Wilks' $\Lambda=0.57$ ). A series of planned contrast analyses was conducted to test the hypotheses.

The results of the contrast analysis of attitude toward the advertisement showed that the promotion-focused individuals evaluated the advertisement more highly than the preventionfocused individuals when they used imagery cues $(M=6.7$ and $M=4.3$, respectively, $t(87)=5.7, p<0.001)$. The preventionfocused individuals, on the other hand, gave the advertisement a higher evaluation when they based their evaluation on analytical cues, in comparison with the promotion-focused individuals $(M=6.3$ and $M=4.2$, respectively, $t(87)=4.8, p<0.001)$.
The promotion-focused individuals gave a higher brand evaluation when they evaluated the imagery advertisement than the prevention-focused group $(M=6.9$ and $M=5.3$, respectively, $t(87)=3.8, p<0.001)$, while the opposite held for their prevention-focused counterpart. $(M=7.1$ and $M=5.0$, respectively, $t(87)=4.5, p<0.001)$. Purchase intention was higher for the imagery condition for promotion-focused subjects in comparison to their counterparts $(M=6.0$ and $M=3.8$, respectively, $t(87)=4.1$, $p<0.001)$. On the other hand, the prevention-focused group showed higher purchase intention for the analytical condition in comparison to promotion-focused subjects $(M=6.1$ and $M=3.5$, respectively, $t(87)=4.6$, $p<0.001)$. The results thus support hypotheses $1 \mathrm{a}$ and $1 \mathrm{~b}$ (means are reported in Table 1).

Process measures. For this study, process measures such as imagery fluency and "style of processing" were matched against the imagery advertising condition, while analytical process measures were used for the analytical advertisement condition. Based on results of a factor analysis, a fluency index was constructed $(\alpha=0.77)$, which was subjected to a one-way ANOVA. Results of a contrast analysis showed that promotion-focused subjects experienced higher fluency when they were exposed to the imagery advertisement than their counterparts $(M=5.9$ and $M=4.7$, respectively, $t(87)=2.8, p<0.01)$. Similarly, on exposure to the analytical advertisement, the prevention-focused subjects experienced higher processing fluency than the promotion-focused subjects $(M=6.3$ and $M=$ 4.7, respectively, $t(87)=3.6, p<0.001)$.

Processing style. Confirming the notion that promotionfocused individuals engage in imagery processing, the results of a one-way ANOVA showed that the promotion-focused individuals did indeed engage in more imagery processing than the prevention-focused individuals when both groups were exposed to the imagery advertisement $(M=4.7$ and $M=$ 2.8 , respectively, $t(87)=4.5, p<0.001)$, while the reverse seem to apply for the prevention-focused individuals on exposure to the analytical advertisement $(M=4.7$ and $M=3.5$, $t(87)=3.1, p<0.05)$. 


\section{Discussion}

The results of the first study show that matching the regulatory focus with a particular type of message cue in advertisements leads to a better attitude toward the advertisement and brand, and it may ultimately result in a higher purchase intention. Moreover, the subjects in different regulatory focus conditions found it easier to process the information when they were provided with matching advertisement types. In terms of information processing styles, there is some preliminary evidence that a particular priming of regulatory focus (e.g., promotion) elicits a preference for a particular information processing style (e.g., imagery).

\section{STUDY 2}

Study 2 tested the robustness of preferences in the absence of images (Bone and Ellen 1992). It also tested the effect of matching focus and advertisement type on an additional dependent variable: message persuasiveness. Finally, information processing measures, such as fluency, together with measures of imagery and analytical processing styles, were included as repeated measures across all the conditions in this study. This would allow a more rigorous test of hypothesis 4 and allow us to test whether the preference for one information processing style over the other is relative or absolute.

In essence, we wanted to not only replicate the results of our first study but also extend it further in terms of theory and application. To this end, a camera was used as the product category for the second study, and imagery versus analytical message characteristics were manipulated through product descriptions (Bolls and Muehling 2007; Bone and Ellen 1992).

\section{Method}

The study used a two (regulatory focus: promotion versus prevention) by two (advertisement type: imagery versus analytical) between-subjects experimental design. This time 84 undergraduate students (52 females, mean age 21.4 years) from a large university in Australia participated in the experiment for a course credit. All the participants were randomly assigned to one of the four conditions.

Product stimulus. Two different kinds of product description—imagery and analytical—for a fictitious brand of camera called "Digishot" were developed following the extant literature (Bolls and Muehling 2007; Bone and Ellen 1992). The camera essentially featured attributes such as megapixels and image processing capability, antishaking and auto macro features, fast shutter speed, high definition (HD) format, and stereo sound. The stimuli are presented in appendix. The stimuli was further subjected to a pretest $(n=25)$ to confirm that the advertisements were indeed perceived as analytical versus imagery ( $M=3.4$ and $M=4.8$, respectively, $p<0.05$ ).

Procedure and measures. The procedure was similar to Study 1. Following regulatory focus priming, subjects completed a manipulation check item (Zhao and Pechmann 2007). In the second part, they evaluated Digishot, a new brand of camera, following which they completed the dependent variables and other process measures.

The key dependent variables, for example, attitude toward brand, purchase intention, and the process measures, used the same items from Study 1. In addition, an additional dependent variable, message persuasiveness, was measured through three items (Not persuasive/Persuasive, Weak arguments/Strong arguments, and Unimportant/Important information) with a 9point Likert scale. Like Study 1, single-item measures of involvement and familiarity with the product category were also included. Cronbach's $\alpha$ values for all the measures ranged from 0.72 to 0.97 .

\section{Results}

Manipulation check. The results of a one-way ANOVA showed that the subjects in the promotion (prevention)-focused conditions were more inclined toward things they "want to do" as opposed to things they "ought to do" in life ( $M=5.9$ and $M=$ 3.3 , respectively, $F(1,82)=47, p<0.001)$.

Dependent measures. Similar to Study 1, familiarity and involvement did not vary significantly across regulatory focus or advertisement type conditions and hence was dropped from further analyses. A MANOVA on the key dependent variables was run to test the key hypotheses simultaneously. The results showed that none of the main effects was significant. As posited, there was a significant interaction between advertisement type and regulatory focus $(F(3,78)=63.9, p<0.001$, Wilks' $\Lambda=0.29$ ).

Results of planned comparison showed that brand evaluation and purchase intentions were higher for promotionfocused group when compared to the prevention-focused subjects $(M=7.4$ and $M=3.5$, respectively, $t(80)=8.9, p<$ $0.001 ; M=7.3$ and $M=3.0$, respectively, $t(80)=9.9, p<$ 0.001 ) in response to the imagery advertisement .The opposite was true for prevention-focused subjects and analytical advertisement condition $(M=7.4$ and $M=4.2, t(80)=7.6, p<$ $0.001 ; M=7.4$ and $M=3.4$, respectively, $t(80)=9.1, p<$ 0.001). Message persuasiveness also showed a similar pattern of results. The promotion-focused subjects exhibited higher message persuasiveness in response to the imagery advertisement than the prevention-focused subjects $(M=6.1$ and $M=$ 5.1 , respectively, $t(80)=2.3, p<0.05)$, while the opposite held for the prevention-focused subjects $(M=6.3$ and $M=$ 4.6 , respectively, $t(80)=4.0, p<0.001)$. A similar pattern of results was thus obtained in Study 2 with respect to the key hypothesis 1, and support was also provided for our second hypothesis on message persuasiveness. All the means are reported in Table 2.

Ease and fluency measures. In Study 2, both imagery and analytical fluency measures were used as repeated measures. Based on factor analysis, items used to measure imagery and 
TABLE 2

Study 2: Dependent Variables as a Function of Regulatory Focus and Ad Type

\begin{tabular}{|c|c|c|c|c|c|c|}
\hline \multirow[b]{2}{*}{ Variables } & \multicolumn{2}{|c|}{ Attitude toward brand } & \multicolumn{2}{|c|}{ Purchase intention } & \multicolumn{2}{|c|}{ Message persuasiveness } \\
\hline & Imagery ad & Analytical ad & Imagery ad & Analytical ad & Imagery ad & Analytical ad \\
\hline Promotion & $\begin{array}{c}7.4 \\
(1.1)\end{array}$ & $\begin{array}{c}4.2 \\
(1.5)\end{array}$ & $\begin{array}{c}7.3 \\
(0.9)\end{array}$ & $\begin{array}{c}3.4 \\
(1.5)\end{array}$ & $\begin{array}{c}6.1 \\
(1.2)\end{array}$ & $\begin{array}{c}4.6 \\
(1.4)\end{array}$ \\
\hline Prevention & $\begin{array}{c}3.5 \\
(1.9)\end{array}$ & $\begin{array}{c}7.4 \\
(0.9)\end{array}$ & $\begin{array}{c}3.0 \\
(1.8)\end{array}$ & $\begin{array}{c}7.4 \\
(1.3)\end{array}$ & $\begin{array}{c}5.1 \\
(1.9)\end{array}$ & $\begin{array}{c}6.3 \\
(0.8)\end{array}$ \\
\hline
\end{tabular}

Note. Figures in parentheses represent standard deviation.

analytical fluencies were aggregated to form an imagery processing fluency index $(\alpha=0.71)$ and an analytical processing fluency index $(\alpha=0.79)$.

A mixed ANOVA was performed with two levels of processing fluency index (imagery and analytical) as the repeated measure and regulatory focus and advertisement type as between-subject factors. The results showed a significant twoway interaction between regulatory focus and advertisement type for all the dependent variables $(F(1,80)=28.1, p<$ $0.001)$.

A comparison of contrast analyses showed that the promotion-focused subjects experienced higher imagery processing fluency when they were exposed to the imagery advertisement than the prevention-focused subjects $(M=6.8$ and $M=4.2$, respectively, $t(80)=6.8, p<0.001)$. Imagery fluency did not differ across the groups when both were exposed to the analytical advertisement $(M=4.9$ and $M=$ 5.4 , respectively, $t(80)=1.1, p>0.05)$.

Similar analyses showed that the prevention-focused subjects experienced more analytical fluency on exposure to the analytical advertisement than their promotion-focused counterparts $(M=7.1$ and $M=5.6$, respectively, $t(80)=3.8, p<$ $0.001)$; however, analytical fluency did not differ when both groups were exposed to the imagery advertisement $(M=4.9$ and $M=4.7$, respectively, $t(80)=0.5, p>0.1)$. The results thus confirm that matching focus with advertisement type enhances fluency but only for the relevant information type.

Mediation analyses. To test hypothesis 3, we used three different models for mediation analyses (Baron and Kenny 1986). In the first model, we used brand attitude as the dependent variable, while the second and third models engaged with purchase intention and message persuasiveness. In line with extant literature (Labroo and Lee 2006), the interaction between focus and advertisement type was used as the independent variable. Based on our findings in the previous section-that matching regulatory focus with advertisement type enhances processing fluency for the relevant information type- the mediation analyses were conducted with matching fluency types.

In our first model, the result of the first regression analysis showed that the hypothesized focus-advertisement interaction with brand attitude was significant $(b=.46, t(82)=4.7, p<$
.001). A second regression analysis showed that the focusadvertisement interaction in the participants' matching processing fluency index was also significant $(b=.42, t(82)=$ $4.2, p<.001)$. A final regression analysis with processing fluency included in the model as a predictor of brand attitude showed that the effect of processing fluency was significant $(b=.57, t(82)=6.5, p<.001)$, whereas the significance level for focus-advertisement interaction decreased $(b=.22, t(82)$ $=2.5, p<.05$, Sobel $z=3.52, p<0.001)$. The second mediation test followed a similar procedure and found a partial mediating effect of processing fluency on purchase intention (Sobel $z=3.39, p<0.001$ ). The third model, however, confirmed a full mediating effect of processing fluency on message persuasiveness (Sobel $z=2.73, p<0.01$ ). The results of our mediation analyses support our third hypothesis.

Information processing style. A full-model mixed ANOVA was conducted with imagery and analytical processing styles as repeated measures and the key independent variables as between-subject factors. The results showed a significant two-way interaction between advertisement type and regulatory focus for the processing style measure $(F(1$, $80)=19.3, p<0.001)$.

The promotion-focused subjects reported more imagery processing than the prevention-focused people when both groups were exposed to the imagery advertisement $(M=$ 5.4 and $M=3.8$, respectively, $t(80)=3.9, p<0.05)$. There were no group differences in imagery processing on exposure to the analytical advertisement $(M=4.0$ and $M=3.3$, respectively, $t(80)=1.8, p>0.05)$. In contrast, the subjects primed with the prevention focus reported more analytical processing than their counterparts when both were exposed to the analytical advertisement $(M=$ 5.9 and $M=4.6$, respectively, $t(80)=4.7, p<0.05)$ but not on exposure to the imagery advertisement $(M=4.4$. and $M=4.0, t(80)=1.5, p>0.05)$. These findings support hypothesis 4 .

\section{Discussion}

The results of Study 2 provide support for all the key hypotheses in the research. Using a different product category 
and advertisement manipulation, the results showed that matching the regulatory focus with a particular advertisement type increased the brand evaluation and purchase intention for a product. Furthermore, the effect of matching the regulatory focus with the advertisement type seemed to help the fluency with which the subjects processed the relevant information and further influenced their judgment. Matching was also found to enhance persuasiveness for the relevant message type, and this effect was again fully mediated by information processability. The results also showed that depending on message attributes and regulatory foci, one style of information processing is usually preferred more than the other.

\section{GENERAL DISCUSSION}

The results across the two experiments found support for the fact that subjects with different regulatory foci have differential preferences for the imagery and analytical information in an advertisement. When a higher-order goal such as regulatory focus is sustained by a certain kind of information or processing style, the resulting goal compatibility influences judgment. The results showed that an advertising message is more (less) persuasive when the content of the message matches (conflicts with) the regulatory goal of the participants. The evidence thus shows that a favorable attitude toward the target brand arises from the fluency in information processing, resulting in a regulatory goal fluency type effect (Labroo and Lee 2006). Convergent and robust evidence across the two studies have been presented in this regard using different dependent measures (attitude in Study 1 and persuasiveness in Study 2), using different advertisement manipulations (image and words in Study 1 versus only words in Study 2), and across different product categories (car and camera).

This study makes important theoretical contributions. First of all, it contributes to the regulatory focus literature, as no extant work has established the fit relationship between regulatory focus and imagery/analytical message attributes. Our finding that goal compatibility enhances processing fluency also extends work done by Labroo and Lee (2006) by showing that a goal fluency effect does indeed underlie persuasion and judgment in the context of regulatory focus and imagery/analytical advertisements. In terms of imagery literature, this study provides evidence of regulatory focus as a moderator of imagery and analytical processing, thereby answering the call to undertake more divergent psychological research on imagery (e.g., Petrova and Cialdini 2008). It also explores a mechanism by which the detrimental effect of imagery elicitation (e.g., imaging instructions) can be avoided. Simply exposing promotion focus to imagery message attributes can trigger imagery and enhance persuasion.

There are several practical implications for managers. First, the results provide insights into specific situations that warrant different advertisement execution styles. For example, a car advertiser may decide to opt for an imagery-based soft-selling style, versus a hard-selling style, focusing on product attributes. Matching this advertisement style with a motivational state may increase the effectiveness of the advertisement. For example, an advertisement for a car may make a prevention goal salient by referencing the family first (Lee, Aaker, and Gardner 2000) and then emphasize a key attribute, such as safety, to encourage analytical processing. An advertiser may, however, benefit from having both types of advertisement (e.g., imagery and analytical) since when presented with conflicting versus compatible information, uninvolved consumers rely on their regulatory focus to make judgments (Wang and Lee 2006).

Advertisers should also pay careful attention to the advertising context. Research shows that a regulatory state can be triggered by the environmental context and external cues (such as a shampoo advertisement showing silky hair) may induce a promotion focus (Labroo and Lee 2006). From this perspective, an imagery advertisement immediately following the shampoo advertisement may obtain more favorable evaluations of the target brand as it promotes fluent processing (Labroo and Lee 2006). A goal conflict, for example, a vitamin advertisement focusing on disease prevention followed by an imagery advertisement of a car, may inhibit processing fluency and result in a lower evaluation and judgment of the target brand.

This research has its limitations. First, we address the concern of potential confounds in the study. We have argued, based on the extant literature, that imagery is closely linked to affect, which may indirectly suggest this as a potential confound in the study. However, we allay this fear based on the following evidence: A considerable amount of literature supports that the operationalization of message characteristics using promotion, hedonic, or even imagery features in advertisements does not necessarily manipulate affect in subjects (Bolls and Muehling 2007; Labroo and Lee 2006; Thompson and Hamilton 2006). Second, the effect of imagery on attitude has been found to be orthogonal to the influence of affect (Escalas 2004; Mani and MacInnis 2001). Third, our operationalization of advertisement type is in line with extant practices (Bolls and Muehling 2007; Thompson and Hamilton 2006; Keller and Block 1997) and ensures that we have not manipulated affect. Affect is typically manipulated by varying the images, illustrations, and color schemes in advertisements (Chowdhury, Olsen, and Pracejus 2008; Pham and Avnet 2004). In contrast, our stimuli held elements such as color and illustration constant across the advertisement type conditions. Fourth, empirical evidence rules out this potential confound too. In neither study did we find a significant main effect of advertisement type on "attitude" or "message persuasiveness," despite these variables having affective and cognitive dimensions.

A second source of confound arises from the potential issue of vividness, which together with "instructions to imagine" has been known to enhance cognitive elaboration (Petrova and Cialdini 2008). In this study, we did not ask subjects to 
imagine the consumption scenario; rather, we showed that advertising effectiveness can be enhanced through matching regulatory foci with a specific information type. This is based on a different argument, such as regulatory fit, rather than the memory-based argument of cognitive elaboration. Cognitive elaboration has been described as the extent to which information in working memory is integrated with prior knowledge structures and may involve activation of associated pathways implying a particular concept (McGill and Anand 1989; MacInnis and Price 1987). The literature suggests that several factors, such as greater product knowledge, increased personal relevance, and instructions to use imagery, may increase cognitive elaboration (Petrova and Cialdini 2005). Empirically, in both of our studies, single-item measures of involvement and familiarity were used as proxies to capture cognitive elaboration (Greenwald and Leavitt 1984). Across both the studies no significant main effect of independent variables on these proxies was found, thereby potentially ruling out this confound. However, single-item proxy variables remain a possible limitation.

This brings us back to the issue of vividness. Vividness is normally operationalized through techniques such as the use of pictures versus words, instructions to imagine (Kisielius and Sternthal 1986), or by creating muted versions of original pictures in advertisements (Petrova and Cialdini 2005). In our advertising stimuli, we held the image constant and manipulated only attribute information. It could be argued that our product descriptions might possibly have influenced vividness. Research evidence shows that the persuasive effect of vividness on judgment is moderated by cognitive elaboration (McGill and Anand 1989; Kisielius and Sternthal 1986). Since we did not find any evidence of cognitive elaboration manipulation, it should be safe to assume that vividness had a null effect. Furthermore, if vividness had an impact, the resultant cognitive elaboration would have undermined persuasion (Kisielius and Sternthal 1986) rather than enhancing it, as our results show.

However, future work may research the proposition of whether regulatory focus moderates the effect of vividness on attitude and persuasion. Unlike our study, future research may manipulate different processing styles through specific instructions and test for their impact on persuasion. Manipulating "vividness" or providing "instructions to imagine" will in turn lead to higher cognitive elaboration, which can specifically be captured through thought listing. This will help scholars understand whether higher mental elaboration under a specific regulatory motivation undermines or enhances persuasion. For example, theory on regulatory focus predicts that it should have a differential impact. Higher elaboration may cause promotion subjects to focus relatively more on positive information (compared to negative information) in memory, thereby enhancing persuasion. For their counterparts, more negative information may be accessed and may lower persuasive impact. Future work may also explore the way affect (cognition) elicited by imagery (analytical) messages may influence different regulatory motivations.

This research needs to be replicated across wider product categories and samples, although products used for this study were relevant and familiar to our student sample. The advertisements used in the first study have both visual and verbal elements that complement each other. Future studies may consider advertisements in which the verbal and visual cues are noncomplementary. Future work may further explore how regulatory focus may affect evaluations of comparative and noncomparative advertisements (Thompson and Hamilton 2006).

\section{REFERENCES}

Aaker, Jennifer L., and Angela Y. Lee (2001), "I Seek Pleasures and We Avoid Pains: The Role of Self-Regulatory Goals in Information Processing and Persuasion," Journal of Consumer Research, 28, 33-49.

Bagozzi, Richard P. (2008), "Some Insights on Visual and Verbal Processing Strategies," Journal of Consumer Psychology, 18 (3), 258-63.

Baron, Reuben M., and D.A. Kenny (1986), "The Moderator-Mediator Variable Distinction in Social Psychological Research: Conceptual, Strategic, and Statistical Considerations," Journal of Personality and Social Psychology, 51, 1173-82.

Bolls, Paul D., and Darrel D. Muehling (2007), "The Effects of Dual-Task Processing on Consumers' Responses to High and Low-Imagery Radio Advertisements," Journal of Advertising, 36 (4), 35-47.

Bone, Paula F., and Pam S. Ellen (1992), "The Generation and Consequences of Communication-Evoked Imagery," Journal of Consumer Research, 19 (1), 93-103.

Chernev, Alexander (2004), "Goal-Attribute Compatibility in Consumer Choice," Journal of Consumer Psychology, 14, 141-50.

Childers, Terry L., Michael J. Houston, and Susan E. Heckler (1985), "Measurement of Individual Differences in Visual versus Verbal Information Processing," Journal of Consumer Research, 12, 125-34.

Chowdhury, M.M.I., Douglas G., Olsen, and John W. Pracejus (2008), "Affective Responses to Print Images in Advertising: Affect Integration in a Simultaneous presentation Context," Journal of Advertising, 37 (3), $7-18$.

Escalas, Jennifer E. (2004), "Imagine Yourself in the Product," Journal of Advertising, 33, 2.

Friedman, Ronald S., and Jens Forster (2001), "The Effects of Promotion and Prevention Cues on Creativity," Journal of Personality and Social Psychology, 81 (6), 1001-13.

Gasper, K. (2004), "Do You See What I See? Affect and Visual Information Processing," Cognitive and Emotion, 18 (3), 405-21.

Greenwald, Anthony G., and Clark Leavitt (1984), "Audience Involvement in Advertising: Four Levels," Journal of Consumer Research, 11, 581-92.

Higgins, Tory E. (1997), "Beyond Pleasure and Pain," American Psychologist, 52 (12), 1280-300.

- Lorraine C. Idson, Antonio L. Freitas, Scott Spiegel, and Daniel C. Molden (2003), "Transfer of Value from Fit," Journal of Personality and Social Psychology, 84 (6), 1140-53.

Hirschman, Elizabeth C., and Morris B. Holbrook (1982), "Hedonic Consumption: Emerging Concepts, Methods, and Propositions," Journal of Marketing, 46 (3), 92-101.

Kees, Jeremy, Scot Burton, and Andrea H. Tangari (2010), “The Impact of Regulatory Focus, Temporal Orientation, and Fit on Consumer Responses to Health-Related Advertising," Journal of Advertising, 39 (1), 19-34.

Keller, Punam A., and Lauren G. Block (1997), "Vividness Effects: A Resource Matching Perspective," Journal of Consumer Research, 24 (3), 295-304. 
_, and Ann L. McGill (1994), "Differences in the Relative Influence of Product Attributes under Alternative Processing Conditions: Attribute Importance versus Attribute Ease of Imaginability," Journal of Consumer Psychology, 8 (1), 29-49.

Kisielius, Jolita, and Brian Sternthal (1986), "Examining the Vividness Controversy: An Availability-Valence Interpretation," Journal of Consumer Research, 12, 418-31.

Labroo, Aparna A., and Angela Y. Lee (2006), "Between Two Brands: A Goal Fluency Account of Brand Evaluation," Journal of Marketing Research, 43 (3), 374-85.

Lee, Angela Y., and Jennifer L. Aaker (2004), "Bringing the Frame into Focus: The Influence of Regulatory Fit on Processing Fluency and Persuasion," Journal of Personality and Social Psychology, 86 (2), 205-18.

- Jennifer L. Aaker, and Wendi L. Gardner (2000), "The Pleasures and Pains of Distinct Self-Construals: The Role of Interdependence in Regulatory Focus," Journal of Personality and Social Psychology, 78, 1122-34.

Lin, Fie, and Fuyuan Shen (2012), "Regulatory Focus and Attribute Framing: Evidence of Compatibility Effects in Advertising," International Journal of Advertising, 31 (1), 169-88.

MacInnis, Deborah J., and Linda L. Price (1987), "The Role of Imagery in Information Processing: Review and Extensions," Journal of Consumer Research, 13 (4), 473-91.

Mani, Gayathri, and Deborah J. MacInnis (2001), "Imagery Instructions, Imagery Processes and Visual Persuasion," in Advertising and Consumer Psychology, R. Batra and O. Scott, eds., Lexington, MA: Lexington Books.

McGill, Ann L., and Punam Anand (1989), "The Effect of Imagery on Information Processing Strategy in a Multiattribute Choice Task," Marketing Letters, 1 (1), 7-16.

Packer, Dominic J., and William A. Cunningham (2009), "Neural Correlates of Reflection on Goal States: The Role of Regulatory Focus and Temporal Distance," Social Neuroscience, 4, 412-25.

Pennington, Ginger L., and Neal J. Roese (2003), "Regulatory Focus and Temporal Distance," Journal of Experimental Social Psychology, 39 (6), 563-76.

Petrova, Petia K., and Robert B. Cialdini (2005), "Fluency of Consumption Imagery and the Backfire Effects of Imagery Appeals," Journal of Consumer Research, 32, 442- 52.

Petrova, Petia. K., and Robert B. Cialdini (2008), "Evoking the Imagination as a Strategy of Influence," in Handbook of Consumer Psychology, Curtis P. Haugtvedt, Paul M. Herr, and Frank R. Kardes, eds., Mahwah, NJ: Lawrence Erlbaum Associates, 505-23.
Pham, Michel T., and Tamar Avnet (2004), "Ideals and Oughts and the Reliance on Affect versus Substance in Persuasion," Journal of Consumer Research, 30 (March), 503-18.

_ , and Tamar Avnet (2009), "Contingent Reliance on the Affect Heuristic as a Function of Regulatory Focus," Organization Behavior and Human Decision Process, 108, 267-78.

Sengupta, Jaideep, and Rongrong Zhou (2007), "Understanding Impulsive Eater's Choice Behaviors: The Motivational Influences of Regulatory Focus," Journal of Marketing Research, 44 (2), 297-308.

Shafir, Eldar, Itamar Simonson, and Amos Tversky (1993), "Reason-Based Choice," Cognition, 49, 11-36.

Smith, Pamela K., and Yaacov Trope (2006), "You Focus on the Forest When You are in Charge of Trees: Power Priming and Abstract Information Processing," Journal of Personality and Social Psychology, 90 (4), 578-96.

Sujan, Mita (1985), “Consumer Knowledge: Effects of Evaluation Strategies Mediating Consumer Judgments," Journal of Consumer Research, 12 (1), $31-45$.

Sung, Yongjun, and Sejung M. Choi (2011), "Increasing Power and Preventing Pain: The Moderating Role of Self-Construal in Advertising Message Framing," Journal of Advertising, 40 (1), 71-85.

Thompson, Deborah V., and Rebecca W. Hamilton (2006), "The Effects of Information Processing Mode on Consumers' Responses to Comparative Advertising," Journal of Consumer Research, 32 (March), 530 40.

Vasquez, Noelia A., and Roger Buehler (2007), "Seeing Future Success: Does Imagery Perspective Influence Achievement Motivation?" Personality and Social Psychology Bulletin, 33 (10), 1392-1405.

Wang, Jing, and Angela Y. Lee (2006), "The Role of Regulatory Focus in Preference Construction," Journal of Marketing Research, 43 (1), 28 38.

Wyer, Robert S., Iris W. Hung, and Yuwei Jiang (2008), "Visual and Verbal Processing Strategies in Comprehension and Judgment," Journal of Consumer Psychology, 18 (4), 244-57.

Zhao, Guangzhi, and Cornelia Pechmann (2007), "The Impact of Regulatory Focus on Adolescents' Response to Antismoking Advertising Campaigns," Journal of Marketing Research, 44, 671-87.

Zhu, Rui, and Joan Meyers-Levy (2007), "Exploring the Cognitive Mechanism that Underlies Regulatory Focus," Journal of Consumer Research, 34, 89-96. 


\section{APPENDIX}

\section{STUDY 1}

Imagery Advertisement

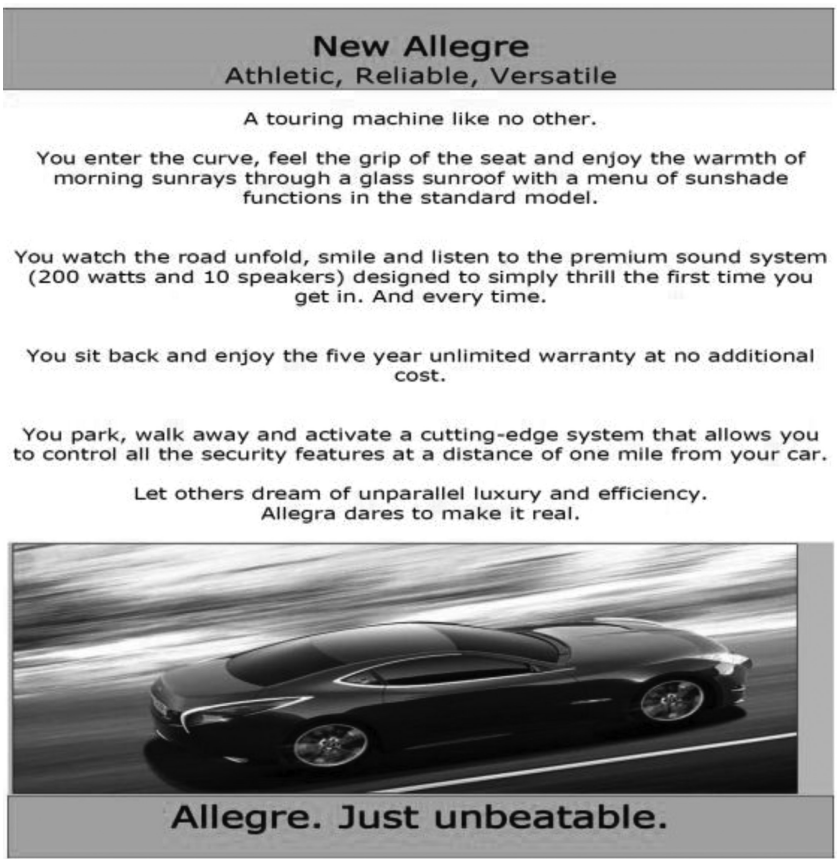

\section{STUDY 2}

Imagery Advertisement

- Create elegant works of art with subtleties of color and lighting. Achieve professional results with features like auto macro and antishaking.

- Capture a friend's bright face, happy smile, and dancing eyes as she poses cheerfully. An unbelievable picture quality made possible with the 16.0 MP sensors and efficient image processors.

- Your feet pound back and forth on the tennis court under the hot sun, you know every split second of every stroke you played is captured by the camera. A $1 / 8000$ to 30 s high speed shutter captures everything clearly, no matter how fast something moves.

- Remember those heart-pounding moments, the screams on the roller coaster ride as it plummeted down the steep track on your last holiday! Now you can play your favorite videos in 720p HD format with stereo sound directly on an HD television.
Analytical Advertisement

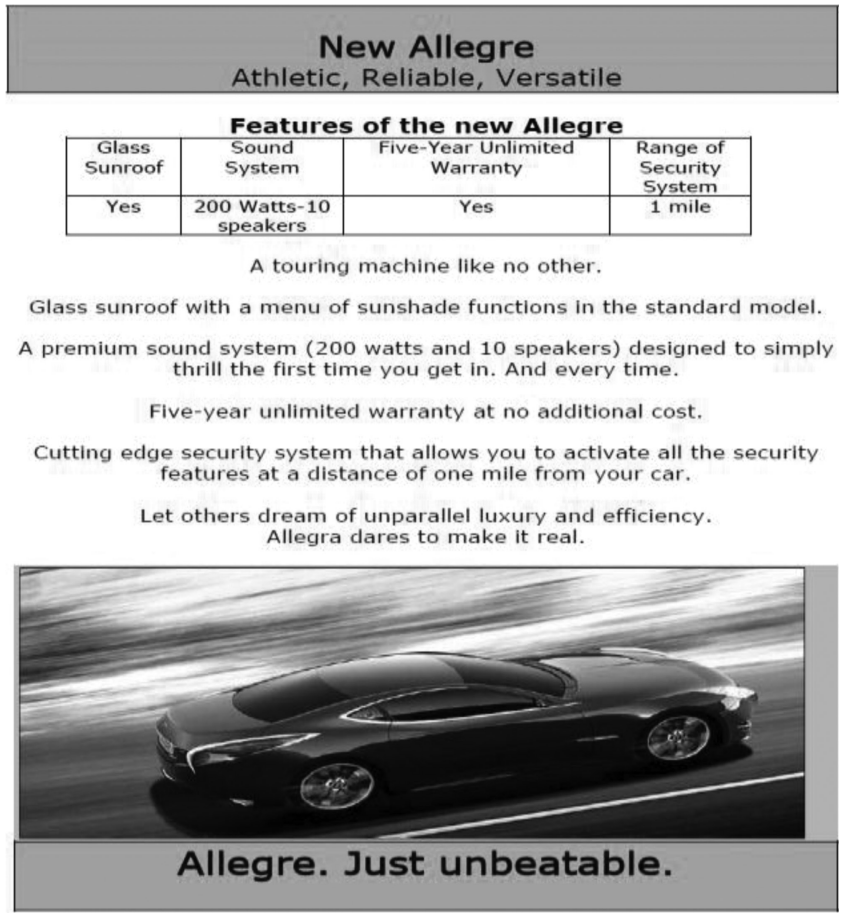

Analytical Advertisement

- Features like auto macro and antishaking help to create works of art and gives you professional results.

- 16.0 MP sensors and efficient image processors capture pictures of special moments with friends with unbelievable quality.

- A 1/8000 to 30s high speed shutter records all the sporting actions clearly, no matter how fast something moves.

- 720p HD video format with stereo sound plays your favorite videos from last holiday directly on an HD television. 